\title{
A synchronic comparison between the vowel phonemes of Bengali \& English phonology and its classroom applicability
}

\author{
ALEEYA TAMZIDA \& SHARMIN SIDDIQUI
}

\begin{abstract}
Due to linguistic diversity, phonologies of the world are notably different from one another, leading the foreign language learners encounter varied phonetic and phonological problems. Bengali speaking EFL learners face problems especially in pronunciation owing to their lack of sound knowledge regarding the distinct positions of phonemes and other aspects of Bengali and English phonology. In this context, our attempt, particularly in this article, is to compare the positions of Bengali and English vowel phonemes and identify the distinctions existing between those in order to help the Bengali speaking EFL learners to improve their pronunciation. Mainly, English vowels (RP) Diagram, Bengali vowels diagram, Cardinal vowels diagram etc have been examined to identify the distinctions mentioned. This paper shows the applicability of our findings by presenting some survey results and suggests some measures to be followed by learners to improve their pronunciation.
\end{abstract}

\section{Introduction:}

Linguistic diversity among different races, leads to a wide variety of phonologies in the world. According to David Abercrombie (1967), 'The phonology of every language is peculiar to that language, and different from that of every other language' (p. 70). And this difference leads the EFL learner face difficulties regarding phonetic, phonological and other aspects of language in speech production and speech perception. Because EFL learners may come across some phonemes or features of the target language which are totally absent from their own phonologies. As a consequence, they suffer from mispronunciation in speech production as well as wrong auditory perception in 
the foreign language.

Bengali speaking EFL learners face problems in pronunciation mainly owing to the lack of knowledge regarding the differences between the phonemes and features of Bengali and English phonology and they fail to handle those English phonemes or features successfully which they are not accustomed to. Then they make some English phonemes identical with some Bengali phonemes leading to mispronunciation as there are far differences between those Bengali and English phonemes. The situation turns severe when the Bengali speaking learners deal with English vowel phonemes. Their lack of proper knowledge about the differences between Bengali and English vowel phonemes affects their pronunciation which can even hamper their general linguistic proficiency. To achieve linguistic proficiency, they should put proper emphasis on pronunciation since pronunciation is an important aspect of language proficiency. Morley (1991) rightly says, "intelligible pronunciation is an essential component of communication competence" (p. 488). Nooteboom (1983) suggests that speech production is affected by speech perception, and stresses the need of pronunciation in both listening and speaking. Tench (1981) rightly opines - pronunciation is not an optional extra for the language learner any more than grammar, vocabulary or any other aspect of language is. If a learner's general aim is to talk intelligibly to others in another language, a reasonable pronunciation is important (p. 1).Wong (1993) feels that a lack of knowledge of pronunciation even affects learners' reading and spelling. Scarcella and Oxford (1994) suggest that pronunciation should be taught in all second (foreign) language classes through a variety of activities. All these remarks can make us feel the momentous importance of pronunciation. Pronunciation has inseparable link with listening and speaking which are two important language skills, but these two skills are still having less importance in spite of the arrival of the communicative language teaching framework in the Bangladesh context. This really goes against the principles of CLT where Diane Larsen - freeman (2000) states, "Students work on an all four skills from the beginning" (p. 130). So, proper emphasis should be put on the pronunciation of Bengali speaking EFL learners. 
To improve pronunciation Bengali speaking EFL learners should learn the differences between the phonemes of Bengali and English language which can help them to avoid mispronunciation. In this context, as an attempt to help the Bengali learners, this study particularly tries to identify the points of differences between the positions of Bengali and English pure vowel phonemes along with some differences between Bengali and English diphthongs. We can divide our study into three parts. At first, our article presents the vowels of Bengali and English phonology in details and studies English vowels (RP) diagram, IPA English vowel chart, Bengali vowel diagram, Bengali IPA chart, Cardinal vowel diagram etc. to identify the differences between Bengali and English vowels. Having observed the diagrams acutely, this study tries to discover and present the points of differences between the positions of Bengali and English vowels along with some differences between the diphthongs. The second part of the study, based on a survey, shows how the findings of first part of this study have been applied on 40 students of a phonetic classroom and what result is achieved. In the third part, our article suggests some measures by which the Bengali speaking EFL learners can apply these learnt differences to improve pronunciation. We think our findings can help the Bengali speaking EFL learners to acquire better pronunciation and avoid mispronunciation.

\section{Brief Description of Bengali and English Vowel Phonemes:}

As an attempt to describe Bengali and English vowel phonemes briefly, this paper presents those vowels through the required charts, diagrams, information, or explanation where necessary. By 'English and Bengali phonemes', we refer particularly to RP English phonemes and the phonemes of standard Bengali respectively in this paper.

\subsection{Bengali Vowel Inventory:}

The vowel inventory of Bengali phonology consists of 14 vowels, including the 7 nasal vowels. Mainly we find 7 oral vowels such as $B[i], G[e], A @ v[Q]$, $A v[a], A[c], I[o], D[u]$ and the total number of vowels reaches 14 when we add nasal quality to these 7 oral vowels. 
Bengali Vowels are presented through an approximate phonetic scheme in International Phonetic Alphabet in the following way:

\begin{tabular}{|l|l|l|l|}
\hline \multicolumn{4}{|c|}{ Bengali Vowels } \\
\hline & Front & Central & Back \\
\hline High & i & & u \\
\hline High-mid & e & & o \\
\hline Low-mid & Q & & J \\
\hline Low & & a & \\
\hline
\end{tabular}

Table 1: Bengali Vowels as presented in International Phonetic Alphabet

The positions of Bengali vowels can be shown in a vowel chart following the indication made by Muhammed Abdul Hay:

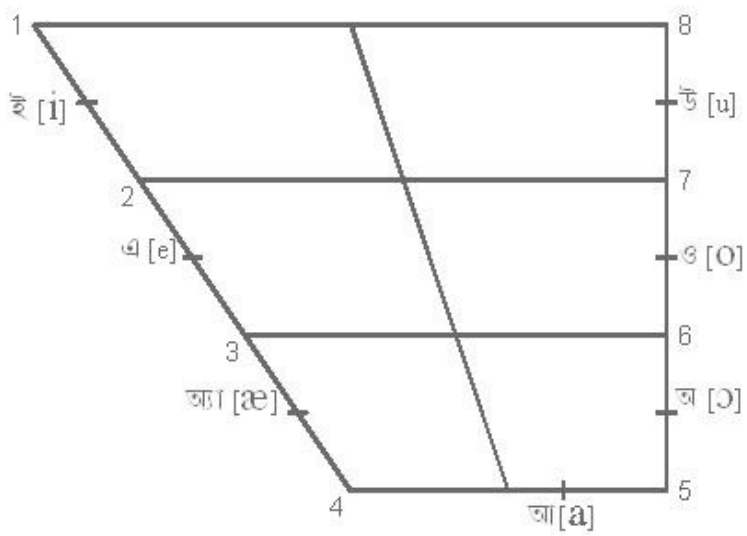

Chart 1: Bengali Vowel Chart following the indication made by Muhammad Abdul Hai

\subsection{English Vowel Inventory:}

The vowel inventory of English phonology consists of 20 vowels among which 12 vowels are pure vowels or monophthongs (which don't glide) and 8 288 
vowels are diphthongs (which consist or glide from one vowel to another).

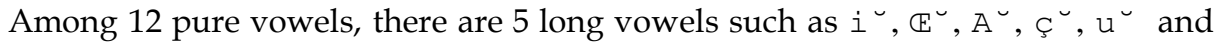
the others are short vowels such as I, e, Q, $V, \AA$, U, and '.

RP English vowels are presented through an approximate phonetic scheme in International Phonetic Alphabet in the following way:

\begin{tabular}{|c|c|c|c|c|c|c|}
\hline \multicolumn{7}{|c|}{ Monophthongs } \\
\hline & \multicolumn{2}{|c|}{ Front } & \multicolumn{2}{|c|}{ Central } & \multicolumn{2}{|c|}{ Back } \\
\hline & long & short & long & short & long & Short \\
\hline Close & $i^{\sim}$ & I & & & $\mathrm{u}^{\sim}$ & U \\
\hline Mid & & e & $3^{u}$ & o & $\rho^{u}$ & \\
\hline Open & & $\mathfrak{x}$ & & $\Lambda$ & $a^{-}$ & $D$ \\
\hline
\end{tabular}

Table 2: English Monophthongs in IPA

The positions of RP English pure vowels (monophthongs) can be shown in a vowel chart in the following way:

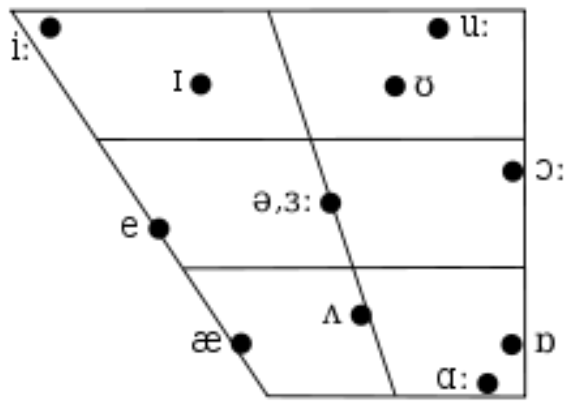

Chart 2: RP English monophthongs 


\subsection{Cardinal Vowels:}

While comparing the positions of Bengali and English pure vowels, we have taken help of cardinal vowels which are a set of reference vowels used by phoneticians in describing the sounds of languages. It is a vowel sound produced when the tongue is in extreme position. This paper shows only the positions of primary cardinal vowels, not the secondary ones.

The positions of cardinal vowels are shown in the following chart:

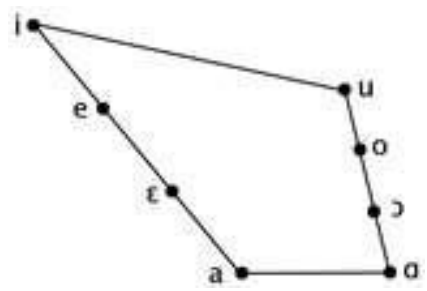

Chart 3: Primary Cardinal Vowels

\subsection{Vowel Classification:}

In this article, five standards for classifying vowels, such as part of the tongue raised, height of tongue, formation of lips, position of velum and state of jaws/ the muscular condition of jaws are considered to analyze English and Bengali vowels.

1. Part of the tongue raised

During the articulation of vowel sounds, different parts of the tongue body front, central and back-are raised horizontally. In this regard, we get three distinctive kinds of vowels.

\subsection{Front vowel}

In the production of front vowels, the tongue is positioned forward in the mouth. For example, in English [i], [æ] and in Bengali [ই], [এ]. 


\subsection{Back vowel}

In back vowels, such as [u:], the tongue is positioned towards the back of the mouth. In English, [u:], [ $\alpha:]$ and in Bengali [অ], [উ], [ও] are some instances of back vowels.

\subsection{Central vowel}

The defining characteristic of a central vowel is that the tongue is positioned halfway between a front vowel and a back vowel. In other words, the state of tongue remains normal. [ओ] in Bengali and [ə] in English are central vowels.

\section{Height of tongue}

According to the height of tongue, we get high vowel, high-mid vowel, low vowel and low-mid vowel. These correspond to the alternative terminology close, close-mid, open-mid and open. The term tongue height is used to refer to the vertical position of the tongue relative to either the roof of the mouth or the aperture of the jaw. The IPA prefers the terms close vowel and open vowel, respectively, which describes the jaw as being relatively open or closed.

\subsection{High vowel/Close vowel}

The defining characteristic of a high vowel is that the tongue is raised as high as possible to the roof of the mouth without creating any obstruction to the flow of air. For example, English [i:], [u:] and Bengali [ই], [উ] are high vowels.

\subsection{Low vowel/ Open vowel}

The tongue is lowered as far as possible from the roof of the mouth in the production of low vowel. English [ $\alpha$ : ] and Bengali [আ] are vowels of this kind.

\subsection{Close mid vowel/High mid vowel}


When we articulate a close-mid vowel such as English [3:] or Bengali [এ], the tongue is positioned two-thirds of the way from a close vowel to a mid vowel.

2.4 Low mid vowel/Open mid vowel

In an open-mid vowel, the tongue is positioned two-thirds of the way from an open vowel to a mid vowel. Some examples of this type of vowel are English [Q],

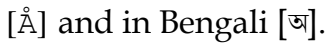

3. Position of Lips

\subsection{Rounded vowel}

A vowel that is pronounced with the lips rounded is called rounded vowel. For

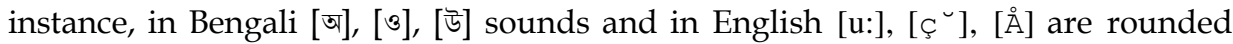
vowels.

\subsection{Spread Vowel}

While pronouncing spread vowels, the corners of the lips are moved away from each other. For instance, [i], [e] and [এ], [ই] are English and Bengali spread vowels respectively.

\subsection{Neutral Vowel}

The articulation of this kind of vowel consists of the neutral position of the lips. Bengali [आ] and English ['], [3:] are some of the neutral vowels. 


\begin{tabular}{|l|l|}
\hline \multicolumn{2}{|c|}{ Position of Lips } \\
\hline Rounded & {$[\mathrm{u}:],[\mathrm{U}],,[\AA]$ ],$[\mathcal{~}:]$} \\
\hline Spread & {$[\mathrm{i}:],[\mathrm{I}],[\mathrm{e}],[\mathfrak{x}]$} \\
\hline Neutral & {$[3:],[\sqrt{ }],[ə],[\mathrm{A}:]$} \\
\hline
\end{tabular}

Table 3: English vowels according to the position of lips

\begin{tabular}{|l|l|}
\hline \multicolumn{2}{|c|}{ Position of Lips } \\
\hline Rounded & [অ], [ও],[উ] \\
\hline Spread & [এ], [ই], [ A®v] \\
\hline Neutral & [আ] \\
\hline
\end{tabular}

Table 4: Bengali vowels in terms of the position of lips

\section{Position of Velum}

When vowels are categorized according to the position of velum, we get two groups of vowels - oral and nasalized. Velum does not have any function while air comes out of the lungs and passes through the mouth during the pronunciation of oral vowel. Velum remains in normal state. But during the articulation of nasalized vowel, velum comes down and allows air to escape through the mouth and nasal cavity simultaneously.

In Bengali alphabet, moon-dot is used on each of the vowels to indicate the nasality of them and in IPA sedila $($,$) is used to do the same.$

In English there is no individual nasalized vowel. Vowels sound before and after nasalized consonant sounds can slightly be articulated in nasalized forms.

\section{Muscular condition of jaws}

According to the condition of jaws we have two kinds of vowels - tense vowels and lax vowels.

\subsection{Tense vowel}

A tense vowel is produced with a relatively strong muscular effort. It involves a greater movement of the upper vocal tract away from the position of rest, and a relatively strong speed of acoustic energy (e.g. high front and high back vowels). 
The tense vowel except schwa in each case is long and may tend to diphthongization. In Bengali, there are no tense vowels.

\subsection{Lax vowel}

Conversely, a lax vowel is produced with less muscular effort and movement, and is relatively short and indistinct (e.g. centralized vowels). Bengali vowels are lax vowels.

In the following table classification of vowels are shown according to the five standards.

\begin{tabular}{|l|l|l|l|l|l|l|l|}
\hline & ₹ & $এ$ & $\mathrm{~A} \Theta \mathrm{V}$ & आ & ज & ও & উ \\
\hline $\begin{array}{l}\text { High vowel/Close } \\
\text { vowel }\end{array}$ & + & - & - & - & - & - & + \\
\hline $\begin{array}{l}\text { Close mid vowel/ } \\
\text { High mid vowel }\end{array}$ & - & + & - & - & - & + & - \\
\hline $\begin{array}{l}\text { Low mid } \\
\text { vowel/Open mid } \\
\text { vowel }\end{array}$ & - & - & + & - & + & - & - \\
\hline $\begin{array}{l}\text { Low vowel/ Open } \\
\text { vowel }\end{array}$ & - & - & - & + & - & - & - \\
\hline $\begin{array}{l}\text { Front vowel } \\
\text { Central vowel }\end{array}$ & + & + & + & - & - & - & - \\
\hline Back vowel & - & - & - & - & + & + & + \\
\hline Rounded vowel & - & - & - & - & + & + & + \\
\hline Spread vowel & + & + & + & - & - & - & - \\
\hline Neutral vowel & - & - & - & + & - & - & - \\
\hline
\end{tabular}


Table 5

\subsection{Semi Vowels}

British Phonetician Daniel Jones (1997) defined a semi-vowel as "a voiced gliding sound in which the speech organs start by producing a vowel of comparatively small prominence and immediately change to more prominent vowel" (p. 4).

There are two semi-vowels in English: /j/, /w/

There are controversies to determine the number of semi-vowels in Bengali. Shunitikumar Chaterjee (1989) and Shukumar Shen (1998) accepted two semivowels --/w/, /y/ in Bengali. But Muhammad Abdul Hai talked of three semivowels in Bengali /w/, /y/, and /i/. Nevertheless, Pobitro Sharker and Ghonesh Boshu (1998) like Ferguson and Munier Chowdhury (1960) admitted the existence of four semi-vowels (p. 32). These four semi-vowels are /i e o u/.

\begin{tabular}{|l|c|}
\hline \multicolumn{2}{|c|}{ Position of the tongue } \\
\hline Front & Back \\
\hline ই $[\mathrm{i}]$ & উ $[\mathrm{u}]$ \\
\hline$\unlhd[\mathrm{e}]$ & ও $[\mathrm{o}]$ \\
\hline
\end{tabular}

Table 6: Semi-vowels suggested by Ferguson and Munier Chowdhury

Despite all these controversies, in Bengali four semi-vowels are acknowledged.

\subsection{Diphthong}

A diphthong, also known as a gliding vowel, is a one-syllable sound that is made up of two adjacent vowel sounds. During the articulation of a diphthong the tongue moves from one position to another, causing a continual change in vowel quality, as in the pronunciation of $a$ in English late, during which the tongue moves from the position of (e) towards (I). 
The total number of English diphthongs is eight. Among the eight diphthongs, three (3) are centering and five closing. Of the five closing diphthongs, two (2) are narrow and three (3) wide.

\begin{tabular}{|l|l|l|}
\hline $\begin{array}{l}\text { Centering } \\
\text { Diphthongs }\end{array}$ & \multicolumn{2}{|l|}{ Closing Diphthongs } \\
\hline /Iə/ & Narrow (2) & Wide (3) \\
\cline { 2 - 3 } & /əI/ & /aI/ \\
/Ua/ & leI/ & /aU/ \\
& & $/$ 'U/ \\
/eə/ & & \\
\hline
\end{tabular}

Table 7: Classification of English Diphthongs

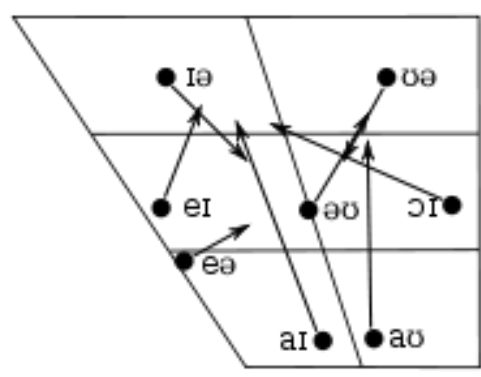

Chart 4: English Diphthongs

Nevertheless, linguists differ as to the number of Bengali diphthongs. They vary from 17 to 31. Muhammad Abdul Hai $(1964,1994)$ told that phonetically 31 diphthongs are there in Bengali language. Among those diphthongs, nineteen (19) are regular and twelve (12) are irregular (p. 36).

But the diphthongs recommended by Pobitro Sharker are more preferable. In Samsad Bangla Uchyaron Ovidan (1992) seventeen (17) diphthongs are accepted. Zinat Imtiaz Ali (2001), along with many other Bengali linguists, supported this number of diphthongs (p. 86). We also think that there are seventeen (17) diphthongs in Bengali language.

\begin{tabular}{|l|l|l|l|}
\hline \multirow{2}{*}{$\begin{array}{l}\text { Serial } \\
\text { number }\end{array}$} & \multicolumn{2}{|l|}{ Diphthongs } & \multirow{2}{*}{ Example } \\
\cline { 2 - 3 } & Bengali alphabet & IPA & \\
\hline 1 & ইই্ & {$[\mathrm{ii}]$} & dii (I give) \\
\hline 2 & ইউุ & {$[\mathrm{iu}]$} & biubhol (upset) \\
\hline 3 & এই & {$[\mathrm{ei}]$} & nei (I take) \\
\hline
\end{tabular}




\begin{tabular}{|c|c|c|c|}
\hline 4 & এউ্ & [eu] & dheu (wave) \\
\hline 5 & $A \otimes V$ ல & [æo] & naeo (you take) \\
\hline 6 & A®Vএ् & [æe] & dae (she gives) \\
\hline 7 & আই & [ai] & khai (I eat) \\
\hline 8 & আঞ্ণ & [ao] & jao (you go) \\
\hline 9 & আউ! & {$[\mathrm{au}]$} & pau (sliced bread) \\
\hline 10 & আএ & [ae] & pae (she finds) \\
\hline 11 & অও্ & [ço] & noo (you are not) \\
\hline 12 & অ@् & [çe] & bhoy (fear) \\
\hline 13 & ওও् & [oo] & shoo (you lie) \\
\hline 14 & ওউ & [ou] & nouka (boat) \\
\hline 15 & ওই & [oi] & boi (book) \\
\hline 16 & उ@् & [oe] & dhoe (she washes) \\
\hline 17 & উই্ট & [ui] & dhui (I wash) \\
\hline
\end{tabular}

Table 10: Diphthongs recommended by Pobitro Sharker

\section{Some points of distinctions between Bengali and English vowel phonemes:}

3.1 Distinctions between the positions of Bengali and English monothongs:

This study examines English vowels (RP) diagram, IPA English vowels chart, Bengali vowels diagram, IPA Bengali vowels chart, cardinal vowels diagram etc and identifies the following differences between the positions of English and Bengali vowels: 


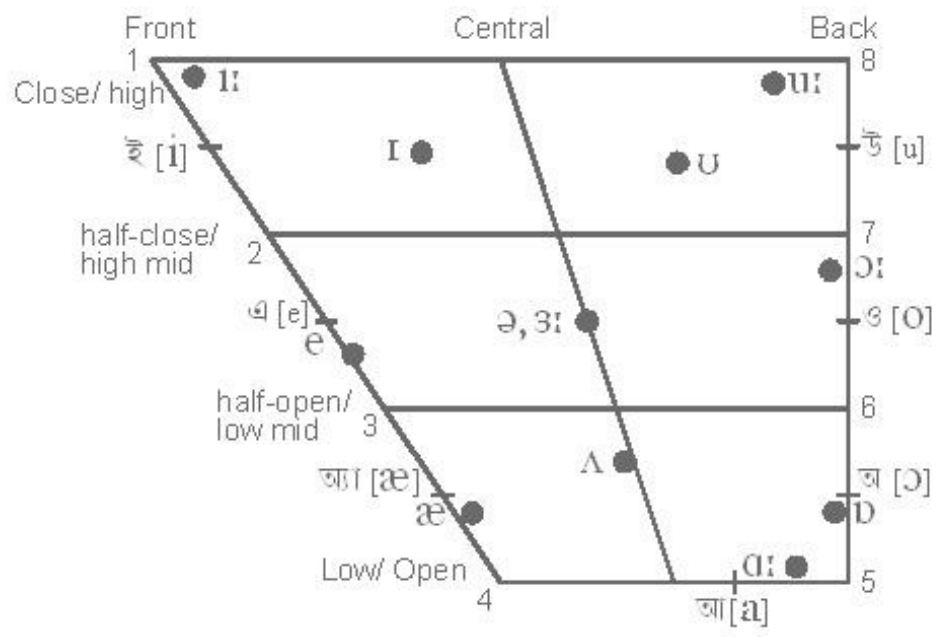

Chart 5: Diagram showing Bengali and English vowels

1.Distinctions among the positions of Bengali vowel/B/[i], English short vowel /I/ and English long vowel /i $\smile$ /:

Bengali /B/ [i] is a close/high vowel according to tongue height, a front vowel according to which part of the tongue is raised and an unrounded vowel according to lip position. The lips are slightly spread or neutral and there is narrow passage between the jaws. The position of $/ \mathrm{B} /$ [i] is in the middle point between cardinal vowel no -1 and 2. For example: /B/ [i] in ' $\mathrm{BU}$ ' [it]. /B/ [i] can have nasal quality sometimes according to the situation and we consider that /B/ [i] with nasal quality as nasal /B/ $[i$,$] in Bengali phonology. For example:$

\begin{tabular}{|l|c|l|l|l|}
\hline Nasal vowel & & Example & & \\
\hline Bengali alphabet & IPA & Bengali & IPA & Meaning \\
\hline $\mathrm{Bu}$ & {$[i]$,} & weuwa & {$[$ bi,d5hi] } & to pierce \\
\hline
\end{tabular}

Table 11 
English short vowel /I/ is also a front vowel but less close (high) than i: and the lip position is slightly spread. It is lower (more open) and more centralized (nearer into the centre) than /i:/ as well as Bengali/B/ [i] and there is less muscular tension in the mandible. So, it is a lax vowel. We have to open our mouth a little more than Bengali/ B / [i] /i/ to produce it. For example, if we compare /I/ of /sit/ and /B/ [i] of ' $\mathrm{BU}$ ' [it], we find that/I/ of /sit/ is more centralized and more open than/B/ [i] of ' $\mathrm{BU}$ ' [it ] which is more front and a little bit closer. The distinction of frontness between Bengali/B/ [i] and English short vowel /I/ is often missed by Bengali EFL learners.

English long vowel /i:/ is a close (high) front vowel. It is more close (high) and front than English short vowel /I/ and nearer to cardinal vowel no-1 but, the lips are slightly spread. It is less close than Bengali /B/ [i] also. While producing this sound the muscles of the tongue and the other organs are kept tense, and so this phoneme is called a tense vowel (opposite to lax vowel). Bengali phonology does not contain long vowel like /i:/. So, Bengali speaking learner face trouble to deal with this.

2. Distinctions between the positions of Bengali /G/ [e] and English short vowel /e/:

Bengali vowel /G/ [e] is a front high-mid (half-close) unround vowel in between half close and half open position and it is just in the middle point between the cardinal vowel no-2 and no-3. The position of lips is from neutral to spread and the opening between the jaws is in medium position. For example: /G/ [e] in ' $G j$ ' [elo]. Nasal /G/ [e] is also present in Bengali phonology. For example:

\begin{tabular}{|l|l|l|l|l|}
\hline Nasal vowel & & Example & & \\
\hline Bengali alphabet & IPA & Bengali & IPA & Meaning \\
\hline Gu & {$\left[e_{,}\right]$} & Guiv & {$[e, r a]$} & They \\
\hline
\end{tabular}


English short vowel /e/ is a front vowel in between half close (high-mid) and half-open (low-mid) position and between cardinal vowel no-2 and no-3. The lips are slightly spread. For example: /e/ in 'set'/set/ and 'best'/best/. This /e/ vowel is a little bit more open than Bengali /G/ [e]. Bengali learners are not aware of this distinction and pronounce English /e/ just like Bengali /G/ [e] leading to mispronunciation. /e/ does not occur at final position.

3. Distinctions between the positions of Bengali /A@V/ [Q] and English short vowel $/ Q /$ :

Bengali /ABV/ [Q] is a front low-mid unround vowel in the middle point between cardinal vowel 3 and 4 . The lip position is from neutral to spread and the opening between jaws is in medium position. For example: /A®v/ [Q] in GKUv [Qkta]. Bengali phonology also contains nasal/A@v/ [Q]. For example:

\begin{tabular}{|l|l|l|l|l|}
\hline Nasal vowel & & Example & & \\
\hline Bengali alphabet & IPA & Bengali & IPA & Meaning \\
\hline A®vu & {$[Q]$,} & U@vuK & {$[t Q, k]$} & Bag \\
\hline
\end{tabular}

Table13

English short vowel $/ Q /$ is a front vowel in between half open (low mid) and open (low) position. Lips are spread. It is nearer to cardinal vowel 4 but not as open as this. For example: /Q/ in 'sat'/sQt/.

But $/ Q /$ is more open (lower) than Bengali vowel/A®v/ [Q]. Bengali learners may find some troubles to deal with English/Q/ due to this difference.

4. Distinctions among the positions of Bengali vowel /Av/ [a], English short vowel / $\sqrt{ } /$ and English long vowel /A $~ /$ :

Bengali vowel /Av/ [a] is a central and open (low) vowel in between cardinal vowel no-4 and 5 having a tendency to be nearer to no- 5 than no- 4 . The 
lip position is neutral and the opening between two jaws becomes wide from medium. For example: /Av/ [a] in 'Avg' [am]. It is more open than English short vowel $/ \mathrm{V} /$ and nearer to English long vowel /a:/ but it is not so back as /a:/ Bengali phonology contains nasal/Av/ [a]. For example:

\begin{tabular}{|l|l|l|l|l|}
\hline Nasal vowel & & Example & & \\
\hline Bengali alphabet & IPA & Bengali & IPA & Meaning \\
\hline Avu & {$[\mathrm{a}]$,} & evuKv & {$[\mathrm{b}, \mathrm{aka}]$} & Curve \\
\hline
\end{tabular}

Table 14

English short vowel $/ / /$ is a central vowel with neutral lip position. It is more open than half open (low mid) tongue height and a little behind the central area. The sound is made in the middle of the mouth with the middle of the tongue. The jaws are not so open. For example: $/ \sqrt{ } /$ in but $/ b \sqrt{ } t / . / \mathrm{J} /$ is less open (lower) than Bengali /Av/ [a] and nearer to centre than /Av/ [a]/. Bengali learners make this vowel more open and thus make it identical with /Av/ [a] leading to mispronunciation.

English long vowel /a:/ is an open (low) vowel with neutral lip position in the region of cardinal vowel no- 5 but not as back as this. It is nearer to Bengali vowel /Av/ [a] but Bengali/Av/ [a] is nearer to centre than /a:/. While making this sound we need more puff of air and more muscular effort but Bengali learners are not conscious about it. Example of this sound: /a:/ in ' $\mathrm{card}^{\prime} / \mathrm{cA} \mathrm{c}^{\mathrm{a}} \mathrm{d} /$.

5. Distinctions between the positions of Bengali /A/ [C] and English short vowel /̊̊:

Bengali /A/ [̧] is a back half open (low mid) round vowel. While producing this sound, the lips are open enough, yet they are fairly round i.e. the lip position is between open and close lip rounding. The opening between jaws is medium. For example: /A/ in ' $e$ " $[$ bçd]. We have nasal/A/ [c] in Bengali phonology. For example: 


\begin{tabular}{|l|l|l|l|l|}
\hline Nasal vowel & & Example & & \\
\hline Bengali alphabet & IPA & Bengali & IPA & Meaning \\
\hline $\mathrm{Au}$ & {$\left[\mathrm{f}, \mathrm{c}^{\mathrm{N}}\right]$} & $\mathrm{Mu}{ }^{`}$ & {$\left[g \mathrm{c}^{\prime} \mathrm{d}\right]$} & Glue \\
\hline
\end{tabular}

Table 15

English short vowel /Å/ is back vowel but it is not fully back. It is between half open and open in tongue height. The lips are slightly rounded. Example words - pot, gone, cross. It is more open than Bengali vowel / A/ [ C ] and it is not as back as /A/ [C] ] i.e. / $\AA /$ is a little bit nearer into centre than Bengali / A/ [ $[$ ] .

6. Distinctions between the positions of Bengali /I/ [o] and English short vowel /ç $ॅ$ :

Bengali /I / [o] is back high mid (half-close) round vowel in the middle point between cardinal vowel no- 6 and 7. There is narrow passage between the two jaws. For example: /I/ [o] in Iiv/ [ora]. Bengali phonology also has nasal /I / [o].For example:

\begin{tabular}{|l|l|l|l|l|}
\hline Nasal vowel & & Example & & \\
\hline Bengali alphabet & IPA & Bengali & IPA & Meaning \\
\hline Iu & {$[0]$,} & Iuiv & {$[0$, ra $]$} & They \\
\hline
\end{tabular}

Table 16

English long vowel /ç $/$ is an almost fully back vowel with quite strong lip rounding in between cardinal vowel no- 6 and 7 but it is closer to 7 . For

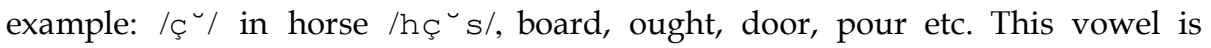
higher/closer than Bengali /I/ [O] and not as back as /I/ [O]. It is a long vowel having longer sound than Bengali /I/ [o] which is certainly short in length. The distinctions of backness, closeness and length between Bengali /I / [o] and English long vowel $/ \varsigma_{\zeta} /$ are often missed by Bengali learners. 
7. Distinctions among the positions of Bengali vowel /D/ [u], English short vowel / U/ and English long vowel $/ \mathrm{u}^{\sim} /$ :

Bengali vowel /D/ $[u]$ is a back, high (close) and round vowel in between cardinal vowel no-7 and 8. We found fairly close lip-rounding in producing this sound and there is opening between the jaws. For example: /D/ $[u]$ in ' $D U$ ' [ut]. Bengali phonology also contains nasal/D/ [u]. For example:

\begin{tabular}{|l|l|l|l|l|}
\hline Nasal vowel & & Example & & \\
\hline Bengali alphabet & IPA & Bengali & IPA & Meaning \\
\hline Du & {$[u]$,} & Ku $\sim$ Wo & {$[k u, r i]$} & A bud \\
\hline
\end{tabular}

Table 17

English short vowel / U/ is back vowel with rounded lip, but it is not fully back. It is nearer to centre and is more open than cardinal vowel $/ \mathrm{u} / . / \mathrm{U} /$ is a lax vowel and less effort is needed for producing this vowel. For example: / U/ in put /pUt/, pull, push, foot, good, wood etc. English vowel / U/ is nearer to centre than Bengali /D/ $[u]$, i.e. /U/ is not as back as /D/ [u]. So, Bengali speaking learners feel some trouble while dealing with English short vowel /U/.

English long vowel /u:/ is close (high) back vowel made with moderately rounded lips. It is a tense vowel and much effort is needed to produce it. It is nearer to cardinal vowel $/ \mathrm{u} /$ but it is less back and less close than cardinal vowel /u/. For example: /u:/ in /fu:d/ food, group, rule, through etc. It is nearer to centre and less open (low) than Bengali vowel /D/ [u]. Bengali phonology does not contain a long vowel like $/ u \circlearrowleft$. So, Bengali learners feel problems to produce $/ u \smile$.

8. In Bengali there is no vowel like English vowel $/ /$ and $/ \mathbb{E} \%$. Both of these are central vowel. /'/ is a central or neutral vowel. It is neither back nor front and neither close nor open. In quality it is mid (that is halfway between close and open) and central (that is halfway between front and back). It is described as lax, because it is produced with less muscular effort and movement i.e. there is less puff of air and less muscular tension in the mandible. It is called schwa by 
some phoneticians. Schwa is never stressed. It is very weak and short at the beginning or in the middle of a word or a group of words spoken without any power between them. For example: /'/ in above, against, miracle, method etc., but it tends to be a little longer and more open if it occurs at the end of a word before a pause such as after, linger, actor.

English long vowel $/ \mathbb{E}^{-/}$is also exactly a central vowel retaining neutral quality. Schwa is actually the shorter form of this long vowel. $/ \mathbb{E}^{-} /$is a tense vowel produced with strong muscular effort and movement i.e. there is more puff of air and much muscular tension in the mandible. The lip position is also neutral. It is well known as hesitation sound (spelt 'er') and it probably is the most difficult English vowel to learn. This vowel has three main spellings, er, ir, ur,

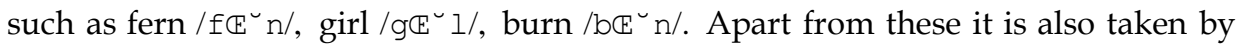
some other spellings such as were, work, earn, learn, serve, journey, flood, does etc.

Since Bengali phonology does not contain these type of central or neutral vowel, Bengali speaking EEL learners face the most difficulty when they deal with English vowel /'/ and $/ \mathbb{E}^{\smile /}$.

\subsection{Differences between Bengali and English diphthongs}

Strong differences can be observed between Bengali and English diphthongs. Bengali diphthongs are characteristically different from and shorter than eight English diphthongs. As a result, Bengali speaking learners pronounces only the first part of a diphthong just like a monothong. For example, mate is pronounced like 'met'.

Since Bengali phonology does not contain /'/ (schwa) vowel, the English diphthongs containing schwa vowels such as $/ I^{\prime} / / e^{\prime} /, / U^{\prime} /$ (centring) and I'U/ (closing) become problematic for Bengali learners. 


\section{The Classroom applicability of the findings of this study:}

Findings of the first part of this study i.e. the distinctions between the positions of Bengali and English pure vowel phonemes along with the differences between Bengali and English diphthongs, have been used in a 'Phonetics' classroom to make learners improve their pronunciation by applying this new knowledge. This part of the study is based on a survey.

\section{Research methodology:}

\subsection{Participants:}

The participants selected for this survey, are 40 undergraduate students undergoing the course 'Introduction to Phonetics and Phonology' in the English Department of Stamford University. 12 students (30\% of the total students) are male and 28 students (70\% of the total students) are female. There age is between 19 and 22. (Mean age 20.5).

\subsection{Data collection procedure:}

The survey is based on the oral feedback of two pronunciation tests containing 20 RP English vowels designed to evaluate the learners' oral production of those vowels. The learners had to appear for two oral tests. After Oral Test 1, learners gained knowledge regarding distinctions between Bengali and English vowel phonemes and then appeared for Oral Test 2, containing different words having RP English vowels arranged in a random way.

The first column of both test formats shows English vowels. The second column cites the example words and the third column shows the phonetic transcription of the example words. A tick mark was put in the fourth column if the oral production of the vowels is correct and in the fifth column if it was not correct.

\subsection{Data analysis procedure:}

The correct and wrong oral responses of the learners evaluated by the teachers in the two oral tests have been calculated and expressed through percentage, 
frequency and mean. Then the differences between the mean of correct answers of the two tests have been depicted through a bar graph to indicate the improvement achieved by the learners in the second test after they received and applied their new knowledge.

\subsection{Results:}

The result of the survey indicates notable improvement achieved by the learners in the second test after gaining and applying their new knowledge regarding the distinctions between Bengali and English vowel phonemes.

Results of oral test-1:

We find the detailed analysis of the oral responses to the first oral pronunciation test through frequency, percentage and average in the following table (Table 1-1).

\begin{tabular}{|c|c|c|c|c|}
\hline \multirow[t]{2}{*}{ VOWEL } & \multicolumn{2}{|c|}{ CORRECT } & \multicolumn{2}{|c|}{ INCORRECT } \\
\hline & $\mathrm{F}$ & $\%$ & $\mathrm{~F}$ & $\%$ \\
\hline I & 1 & $2.5 \%$ & 39 & $97.5 \%$ \\
\hline $\bar{e}$ & 8 & $20.0 \%$ & 32 & $80.0 \%$ \\
\hline $\mathrm{Q}$ & 20 & $50.0 \%$ & 20 & $50.0 \%$ \\
\hline$\sqrt{ }$ & 12 & $30.0 \%$ & 28 & $77.0 \%$ \\
\hline$\AA$ & 32 & $80.0 \%$ & 8 & $20.0 \%$ \\
\hline $\bar{U}$ & 16 & $40.0 \%$ & 24 & $60.0 \%$ \\
\hline & $\overline{0}$ & $0.0 \%$ & 40 & $100.0 \%$ \\
\hline$i^{\sim}$ & 12 & $30.0 \%$ & 28 & $770.0 \%$ \\
\hline $\mathbb{E}^{-}$ & 0 & $0.0 \%$ & 40 & $100.0 \%$ \\
\hline$A^{\lrcorner}$ & 36 & $90.0 \%$ & 4 & $10.0 \%$ \\
\hline $\bar{\zeta}^{\sim}$ & 1 & $2.5 \%$ & 39 & $97.5 \%$ \\
\hline$u^{\sim}$ & 16 & $40.0 \%$ & 24 & $60.0 \%$ \\
\hline
\end{tabular}




\begin{tabular}{|c|c|c|c|c|}
\hline$"$ & 2 & $5.0 \%$ & 38 & $95.0 \%$ \\
\hline e & 2 & $5.0 \%$ & 38 & $95.0 \%$ \\
\hline $\mathrm{U}^{\prime}$ & 2 & $5.0 \%$ & 38 & $95.0 \%$ \\
\hline e" & 4 & $10.0 \%$ & 36 & $90.0 \%$ \\
\hline $\mathrm{a} "$ & 28 & $70.0 \%$ & 12 & $30.0 \%$ \\
\hline Ç" & 4 & $10.0 \%$ & 36 & $90.0 \%$ \\
\hline${ }^{\prime} \mathrm{U}$ & 2 & $5.0 \%$ & 38 & $95.0 \%$ \\
\hline $\mathrm{aU}$ & 28 & $70.0 \%$ & 12 & $30.0 \%$ \\
\hline \multicolumn{2}{|c|}{ AVERAGE } & $28.3 \%$ & & $71.8 \%$ \\
\hline
\end{tabular}

Table 1-1: Results of oral test-1

Table 1-1 shows us that in average $28.3 \%$ students made correct pronunciation of $20 \mathrm{RP}$ vowels and $71.8 \%$ gave wrong pronunciation i.e. the average percentage of the learners making wrong pronunciation of 20 English vowels (RP) is much higher than that of the learners making correct pronunciation.

Results of Oral Test-2:

Detailed analysis of the oral responses to the second oral pronunciation test can be found in the following table (Table 1-2).

\begin{tabular}{|c|c|c|c|c|}
\hline VOWEL & \multicolumn{2}{|c|}{ CORRECT } & \multicolumn{2}{c|}{ INCORRECT } \\
\hline & $\mathrm{F}$ & $\%$ & $\mathrm{~F}$ & $\%$ \\
\hline $\mathrm{I}$ & 22 & $55.0 \%$ & 18 & $45.0 \%$ \\
\hline $\mathrm{e}$ & 24 & $60.0 \%$ & 16 & $40.0 \%$ \\
\hline $\mathcal{Q}$ & 28 & $70.0 \%$ & 12 & $30.0 \%$ \\
\hline$\sqrt{\AA}$ & 26 & $65.0 \%$ & 14 & $35.0 \%$ \\
\hline \multirow{2}{*}{36} & $90.0 \%$ & 4 & $10.0 \%$ \\
\hline
\end{tabular}




\begin{tabular}{|c|c|c|c|c|}
\hline $\mathrm{U}$ & 26 & $65.0 \%$ & 14 & $35.0 \%$ \\
\hline & 18 & $45.0 \%$ & 22 & $55.0 \%$ \\
\hline$i^{\smile}$ & 26 & $65.0 \%$ & 14 & $35.0 \%$ \\
\hline $\mathbb{E}^{\smile}$ & 18 & $45.0 \%$ & 22 & $55.0 \%$ \\
\hline$A^{\sim}$ & 38 & $95.0 \%$ & 2 & $5.0 \%$ \\
\hline$\overline{C^{\sim}}$ & 22 & $55.0 \%$ & 18 & $45.0 \%$ \\
\hline $\mathrm{u}^{\sim}$ & 24 & $60.0 \%$ & 16 & $40.0 \%$ \\
\hline$"$ & 24 & $60.0 \%$ & 16 & $40.0 \%$ \\
\hline$e^{\prime}$ & 24 & $60.0 \%$ & 16 & $40.0 \%$ \\
\hline $\mathrm{U}^{\prime}$ & 24 & $60.0 \%$ & 16 & $40.0 \%$ \\
\hline e" & 32 & $80.0 \%$ & 8 & $20.0 \%$ \\
\hline a" & 36 & $90.0 \%$ & 4 & $10.0 \%$ \\
\hline Ç" $^{\prime \prime}$ & 22 & $55.0 \%$ & 18 & $45.0 \%$ \\
\hline${ }^{\prime} \mathrm{U}$ & 24 & $60.0 \%$ & 16 & $40.0 \%$ \\
\hline $\mathrm{aU}$ & 36 & $90.0 \%$ & 4 & $10.0 \%$ \\
\hline \multicolumn{2}{|c|}{ AVERAGE } & $66.3 \%$ & & $33.8 \%$ \\
\hline
\end{tabular}

Table 1-2: Results of oral test- 2

Table 1-2 shows sharp increase in the number of learners producing correct pronunciation of $20 \mathrm{RP}$ vowels $(66.3 \%)$ and sharp decrease in that of learners making wrong pronunciation of those (33.8\%).

The difference between the average percentages of the learners making correct pronunciation of the $20 \mathrm{RP}$ English vowels of the two oral tests reflects the improvement in the level of pronunciation achieved by the learners after the application of their new knowledge regarding the distinctions between Bengali and English Vowel phonemes, gained after oral test-1. In test-1, the average percentage of the learners making correct pronunciation of the vowel is only $28.3 \%$ whereas it 
is $66.3 \%$ in oral test-2. Similarly the average percentage of learners making wrong pronunciation is $71.8 \%$ in oral test- 1 but only $33.8 \%$ in oral test- 2 . The difference between the percentages of the learners making correct production of each vowel in the two oral tests indicating to this improvement in the level of pronunciation of the learners can be presented through the following line chart of graphic presentation.

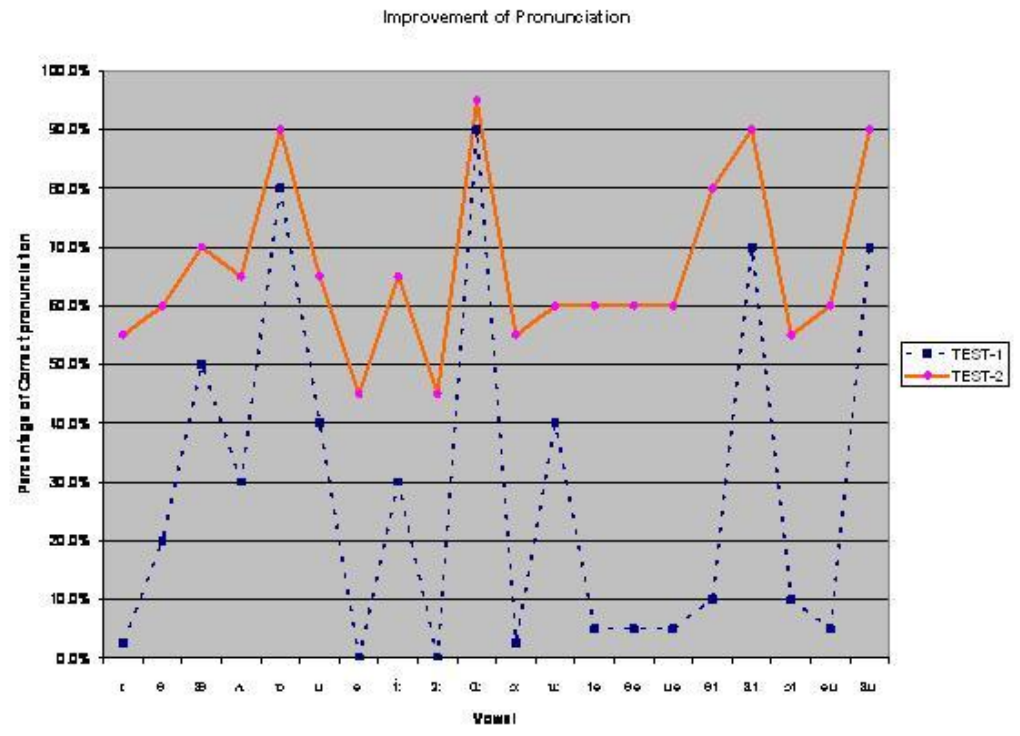

The difference between the two graph lines showing the percentage of the learners making correct pronunciation of the 20 RP English vowels clearly indicates that the learners made massive improvement in their pronunciation by applying their new knowledge gained after oral Test-1.

\section{Recommendations:}

Based on the observations of this study, this paper suggests the following suggestions to be followed by Bengali speaking EFL learners. Bengali speaking learners should- 
- gain clear concepts regarding the distinct positions of Bengali \& English vowel phonemes and practice on those regularly by using mirrors to see the tongue positions while producing those.

- put more muscular effort to produce RP English long vowels (tense).

- Pay conscious effort to produce the central/neutral and lax vowel /'/ (schwa) and make it in the middle of the mouth with the middle of the tongue.

- $\quad$ produce /I/sound in a position of tongue which is nearer to centre and with more open tongue height than that of Bengali / $\mathrm{C} /$ and remember the distinction between /e/ and /Q/ in English.

- make the first part of English diphthongs longer unlike that of Bengali diphthongs.

- remember not to make English vowels nasalized which are devoid of nasality.

- practice the oral production of different vowel phonemes using different software or CDs containing the production of RP vowels.

\section{Conclusion:}

The findings of this study actually reflect a slice of the present scenario prevailing in the field of speech production and speech perception by EFL learners of Bangladesh. Having no sound knowledge regarding the differences of Bengali and English phonemes and other aspects, Bengali speaking learners lead to mispronunciation which hampers their overall linguistic proficiency. In order to help the EFL learners to improve their pronunciation, at least to some extent, this study endeavors to identify the points of distinctions between Bengali and English vowels so that Bengali speaking EFL learners can receive this new knowledge and apply this to improve their pronunciation. This study proves the applicability of these findings by presenting survey results which mark the improvement made by 
40 students after they have applied those findings in learning pronunciation of vowels phonemes. This study also discusses some problems faced by Bengali speaking EFL learners and suggests some measures which can be followed by Bengali learners to overcome their problems regarding pronunciation.

Bengali speaking EFL learners can be benefited by applying this knowledge in learning pronunciation. If they have to achieve linguistic proficiency, they should put due emphasis on pronunciation since negligence in pronunciation can even hamper their overall linguistic proficiency. We hope for the day to come when pronunciation which is the crucial part of communication, would receive its due honor and secured position instead of the peripheral position it has just now in the present context. 


\section{Works Cited}

Abercrombie, D. (1967). Elements of general phonetics. Edinburgh: Edinburgh University Press.

Ali, I.Z. (2001). Dhanibijnaner bhumika. 1st ed. Dhaka: Mowla Brothers.

Chatterjee, S. (1989). Bhasha prakash Bangala bakaran. Kolkata: Rupa \& Company.

Hai, A. M. (1994). Muhammad Abdul Hai rachanaboli. First part. Dhaka: Bangla Academy. Jones, D. (1997). An outline of English phonetics. New Delhi: Kalyani Prakashani.

Larsen Freeman, D. (2000). Techniques and principles in language teaching. New Delhi: Oxford University Press.

Morley, J. (1991). “The pronunciation component in teaching English to the speakers of other languages." TESOL Quarterly, 25 (3), 481 - 520.

Nooteboom, S. (1983). “Is speech production controlled by speech perception?" InVan den Broeck et al. (Ed), Sound Structure. Dordrecht: Foris.

Sarkar, P. (1985-86). "Bangla Dishordhoni." Bhasha (Chaturtha-Pancham Barsha). Kolkata.

Sarkar, P \& Bashu, G. (1989). Bhasha Jiggasha. Kolkata: Biddasagar Pustak Mandir.

Scarcella, R \& Oxford, R. L. (1994). “Second language pronunciation: state of the art in instruction." System, 22 (2), 221- 230.

Sen, S. (1993). Bhashar itibritto. Kolkata: Ananda Publishers Private Limited.

Tench, P. (1981). Pronounciation skills. London and Basingstoke: Macmillan.

Wong, R. (1993). “Pronunciation myths and facts." English Teaching Forum, October Issue, $45-46$. 


\section{Appendix}

ORAL TEST - 1

\begin{tabular}{|c|c|c|c|c|}
\hline $\begin{array}{l}\text { English } \\
\text { Vowels }\end{array}$ & $\begin{array}{c}\text { Example } \\
\text { words }\end{array}$ & $\begin{array}{c}\text { Phonemic } \\
\text { Transcription }\end{array}$ & $\begin{array}{c}\text { Correct } \\
\text { pronunciation }\end{array}$ & $\begin{array}{c}\text { Incorrect } \\
\text { pronunciation }\end{array}$ \\
\hline I & sit & sIt & & \\
\hline e & set & set & & \\
\hline$Q$ & sat & $s Q t$ & & \\
\hline$\sqrt{ }$ & but & $b \sqrt{t}$ & & \\
\hline$\AA$ & pot & pÅt & & \\
\hline $\mathrm{U}$ & put & pUt & & \\
\hline r & about & ( & & \\
\hline i & seat & $\begin{array}{c}s i^{\smile} \\
t\end{array}$ & & \\
\hline $\mathbb{E}^{\smile}$ & bird & $b E^{\smile d}$ & & \\
\hline$A^{\smile}$ & card & $c A^{\sim} d$ & & \\
\hline $\mathrm{C}$ & horse & $h c^{\circ} \mathrm{s}$ & & \\
\hline$u^{\smile}$ & soon & su`n & & \\
\hline "' & peer & $p^{\prime \prime} r$ & & \\
\hline$e^{\prime}$ & fair & fe'r & & \\
\hline$U^{\prime}$ & tour & $t U^{\prime} r$ & & \\
\hline e" & page & pe"g & & \\
\hline a" & kind & ka"nd & & \\
\hline Ç" & boy & bç" & & \\
\hline U & go & $g^{\prime} \mathrm{U}$ & & \\
\hline $\mathrm{aU}$ & now & naU & & \\
\hline
\end{tabular}


ORAL TEST - 2

\begin{tabular}{|c|c|c|c|c|}
\hline $\begin{array}{l}\text { English } \\
\text { Vowels }\end{array}$ & $\begin{array}{c}\text { Example } \\
\text { words }\end{array}$ & $\begin{array}{c}\text { Phonemic } \\
\text { Transcription }\end{array}$ & $\begin{array}{c}\text { Correct } \\
\text { pronunciation }\end{array}$ & $\begin{array}{c}\text { Incorrect } \\
\text { pronunciation }\end{array}$ \\
\hline$u^{u}$ & shoot & $t^{\sim} u s$ & & \\
\hline$U^{\prime}$ & poor & $p U^{\prime} r$ & & \\
\hline $\mathcal{S}^{\smile}$ & short & $t^{\sim}{ }^{\sim} \mathrm{S} S$ & & \\
\hline $\mathrm{U}$ & push & pUS & & \\
\hline Q & hat & hQt & & \\
\hline $\mathbb{E}^{-}$ & purse & $\mathrm{p} \mathbb{E}^{\sim} \mathrm{s}$ & & \\
\hline$i$ & feel & $\begin{array}{c}\mathrm{fi}^{-} \\
\mathrm{l}\end{array}$ & & \\
\hline I & hit & hIt & & \\
\hline$e^{\prime}$ & share & $r^{\prime} e s$ & & \\
\hline e" & cage & $c e " g$ & & \\
\hline e & net & net & & \\
\hline$A^{-}$ & farm & $f A^{\sim} m$ & & \\
\hline$a U$ & proud & praUd & & \\
\hline$a^{\prime \prime}$ & mind & ma"nd & & \\
\hline$\sqrt{ }$ & some & $\mathrm{s} \sqrt{ } \mathrm{m}$ & & \\
\hline 'U & home & $h^{\prime} \mathrm{Um}$ & & \\
\hline , & affect & fekt & & \\
\hline$"$ & fear & f"'r & & \\
\hline ఢ̧" & toy & $t_{c ̧} "$ & & \\
\hline$\AA$ & hot & hÅt & & \\
\hline
\end{tabular}

